\title{
INGENIERÍA BÁSICA PARA EL PROCESO DE GENERACIÓN DE BIOGÁS, A PARTIR DE PORQUINAZA
}

\section{BASIC ENGINEERING FOR GENERATION PROCESS OF BIOGAS FROM PIG MANURE}

\author{
Julio Cesar Ramírez, ${ }^{1}$ Yanneth Parra M., ${ }^{2}$ Ángela María Zárate Chaves, ${ }^{3}$ \\ Cristhian A. Moreno Bernal ${ }^{4}$
}

RESUMEN

En este proyecto se analiza la eficiencia de tres tratamientos a biodigestores por medio del cálculo y análisis de parámetros, entre ellos, la demanda química de oxígeno, sólidos suspendidos, sólidos fijos, sólidos volátiles, $\mathrm{pH}$, temperatura y producción de biogás, teniendo en cuenta que se trabajará con residuo orgánico de cerdo (porquinaza), a partir del cual se determina el que debe ser utilizado en una finca ubicada en Tocancipá, Cundinamarca. Partiendo de la experimentación, se realiza la ingeniería básica para este tipo de sistemas, donde se determinan las dimensiones del biodigestor, contando con que la producción de gas diaria, según las características, tanto del alimento como de la finca, es de 4,023 $\mathrm{m}^{3}$, con una capacidad calorífica de 14084,64 Kcal/día, lo que permite realizar comparaciones de tipo técnico y económico, con la situación actual de la finca. Se concluye que el proyecto es viable desde el punto de vista financiero y de de requerimientos energéticos, y dependería única y exclusivamente de la disponibilidad de recursos de los dueños de la finca, para realizar la inversión, la cual obedece a un monto de \$1'716.300.

Palabras clave: biogás, biodigestor, capacidad calorífica, eficiencia, inversión, demanda química de oxígeno, porquinaza.

\section{ABSTRACT}

The study of this project examines the effectiveness of three treatments biodigestors by means of calculation and analysis of parameters such as chemical oxygen demand, suspended solids, fixed solids, volatile solids, $p H$, temperature and biogas production, taking into account that work with organic waste from pig (porquinaza), from where it determines what should be used in a farm in Tocancipá, Cundinamarca. Based on experimentation continues to perform

\footnotetext{
1 Ingeniero Químico, MSc., Docente Programa de Ingeniería Ambiental y Sanitaria, Facultad de Ingeniería, Universidad de la Salle, Colombia. jcramirez@unisalle.edu.co.

2 Ingeniera Química, MSc., Docente Programa de Ingeniería Ambiental y Sanitaria, Facultad de Ingeniería, Universidad de la Salle, Colmbia. yparra@unisalle.edu.co.

3 Ingeniera Química. Universidad de América. Colombia.

4 Ingeniero Químico. Universidad de América. Colombia.
} 
the basic engineering for this type of system, which determined the size of the biodigestor, with the daily production of gas according to the characteristics of both the food and the farm is $4.023 \mathrm{~m}^{3}$, with a heat capacity of $14084.64 \mathrm{Kcal} / \mathrm{day}$, which allows for comparisons of technical and economic, with the current situation of the farm. Finally concluding with the project is viable in both financial factors as energy requirements, and depend solely on the availability of resources of the owners of the property, for investment of \$1'716 .300.

Key words: biodigestor, efficiency, financial, Chemical Oxygen Demand, heat capacity, porquinaza.

Aprobado: Junio 29 de 2010

\section{INTRODUCCIÓN}

En las fincas de crianza porcina, los residuos sólidos orgánicos suelen ser un problema, ya que estos se encuentran en pozos sépticos los cuales favorecen la generación de plagas y la concentración de malos olores, lo que se convierte en un foco de patógenos. Los residuos orgánicos al ser introducidos en un biodigestor se descomponen, de modo que el ciclo natural se completa y los residuos orgánicos se convierten en bioabono y biogás. El campo de la Ingeniería Química tiene la responsabilidad y el compromiso de guiar cualquier tipo de proceso de una manera amigable con el medio ambiente, logrando así, no solo la preservación del mismo, sino una obtención de beneficios productivos y económicos, sin dejar de lado que este campo involucra también el diseño de procesos y equipos. De tal manera que una adecuada opción para obtener un mejor rendimiento de estos residuos en la finca Veraguas, ubicada en el municipio de Tocancipá, Cundinamarca, es un biodigestor, que ofrece una serie de ventajas medioambientales y económicas, como: producción de biogás (el cual puede ser usado como combustible); mejora de la capacidad fertilizante del estiércol; el lodo producido en el proceso genera un efluente rico en nutrientes, aprovechados directamente por las plantas. De esta manera, se permite el tratamiento de los desechos orgánicos de las explotaciones agropecuarias y disminuye su carga contaminante.

De continuar usando un pozo séptico en la finca como se ha venido haciendo por varios años, se seguiría desperdiciando la materia prima (residuos orgánicos porcinos) y se estaría desaprovechando para obtener beneficios, tales como biogás y bioabono; de la misma forma, no se estaría pensando en una disminución de costos, ya que el biogás podría ser una alternativa de energía para uso interno de la finca. Inicialmente, se da a conocer la metodología para llevar a cabo tanto el proceso de experimentación, como la medición de los diferentes parámetros que se deben tener en cuenta durante este procedimiento; se continua con los resultados y análisis de los mismos, soportados con sus respectivas gráficas y/o tablas. Finalmente, se presentan las conclusiones y recomendaciones. 


\section{METODOLOGÍA}

Para llevar a cabo el proceso de producción de biogás a partir de los residuos orgánicos de las cocheras, se tomó la decisión de realizar 3 experimentos, cada uno con un tratamiento diferente. Uno con adición de microorganismos eficientes, otro con adición de un aislante térmico y, el último, trabajando normalmente.

Se hicieron las tomas de muestras, tanto del alimento, para realizar su respectiva caracterización física y microbiológica definiendo si era apropiado para trabajar en este tipo de proceso, como del efluente en cada uno de los experimentos para evaluar variables de respuesta como demanda química de oxígeno (DQO), sólidos suspendidos, fijos y volátiles, composición del biogás, $\mathrm{pH}$ y temperatura, teniendo en cuenta que estas dos últimas, se miden directamente del sistema.

\section{ANÁLISIS DE RESULTADOS}

\section{Caracterización fisicoquímica del alimento}

Tabla 1. Parámetros de caracterización de la porquinaza

\begin{tabular}{|l|c|l|c|}
\hline \multicolumn{1}{|c|}{ PARÁMETRO } & COMPOSICIÓN (g/L) & \multicolumn{1}{|c|}{ PARÁMETRO } & COMPOSICIÓN (g/L) \\
\hline Nitrógeno Total (N) & 6,27 & Hierro $(\mathrm{Fe})$ & 0,76 \\
\hline Fósforo Total (P2O5) & 9,62 & Cobre $(\mathrm{Cu})$ & 0,04 \\
\hline Carbono Total Oxidable (C) & 94,83 & Manganeso $(\mathrm{Mn})$ & 0,08 \\
\hline Relación C/N & 15,12 & Zinc $(\mathrm{Zn})$ & 0,54 \\
\hline Potasio $(\mathrm{K} 2 \mathrm{O})$ Soluble en Agua & 4,55 & Sólidos Suspendidos & 219,0 \\
\hline Calcio $(\mathrm{CaO})$ & 6,39 & pH & 7,1 \\
\hline Magnesio $(\mathrm{MgO})$ & 5,13 & Densidad Real & 1.205 \\
\hline
\end{tabular}

Fuente. AGROSOIL LAB. Registro ICA para el control de calidad de fertilizantes: Resolución 01320 de Junio de 2004.

Según los datos obtenidos, estos se encuentran en un rango normal debido a varios factores, entre otros, el tipo de alimento que consume el animal, el tipo de agua que se utiliza para limpiar las cocheras, el modo de recolección de la porquinaza.

Por otro lado, los cerdos son ineficientes al asimilar nutrientes y desperdician altos porcentajes de alimento; por esta razón, cerca del 1,3\% de su excreta contiene nitrógeno, fósforo y potasio que son fertilizantes primarios; otro $1,2 \%$ está constituido por fertilizantes secundarios como calcio, cloro, azufre, sodio, etc. Según la relación carbono/nitrógeno $(\mathrm{C} / \mathrm{N})$ obtenida en la caracterización, este afluente está dentro de los parámetros establecidos y dicha relación va a permitir una adecuada multiplicación de la comunidad bacteriana y una velocidad de producción de biogás óptima. 
Otro factor que interviene en la caracterización de la materia orgánica es el pH, el cual al encontrarse dentro de unos valores viables, permite inferir que el proceso de estabilización de la fase metanogénica se obtendrá con mayor rapidez, teniendo en cuenta que las condiciones de temperatura deben ser favorables para que esto se lleve a cabo.

\section{Caracterización microbiológica del alimento}

Esta caracterización se llevó a cabo basándose en la morfología de las bacterias que se encuentran en la carga microbiana, por medio de la tinción de Gram. De tal manera, que en el alimento se evidenció la presencia de una gran cantidad de bacilos Gram negativos como se muestra en la figura 1.

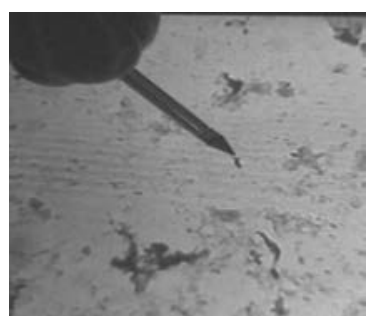

(a) Bacilos Gram positivos.

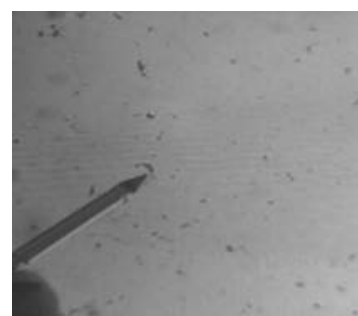

(b) Bacilos Gram negativos.

Figura 1. Carga microbiana para el alimento

Este mismo análisis se realizó para el efluente de cada uno de los diferentes biodigestores experimentales y se encontró que la carga microbiana de estos reflejaba una mayor cantidad de bacilos Gram negativos en comparación con el alimento como se muestra en la figura 2, lo que nos indica que hay un crecimiento microbiano que favorece la producción de gas. Esto quiere decir que las bacterias metanogénicas que se encuentran en estos digestores son en su mayoría Gram negativas; cabe aclarar que dentro de las Gram positivas también se encuentran bacterias metanogénicas que complementan la digestión de la materia orgánica, lo que garantiza que existe un ambiente anaerobio favorable y producción de $\mathrm{CH}_{4}$.

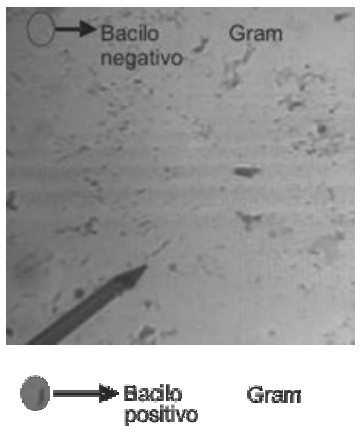

Figura 2. Carga microbiana efluente para digestores experimentales 


\section{Demanda química de oxígeno para el efluente}

Siguiendo la metodología descrita se obtuvo el compendio de datos de la tabla 2.

Tabla 2. Resultados de laboratorio para DQO

\begin{tabular}{|c|c|c|c|c|}
\hline & & BEN & BEA & BEM \\
\hline Tiempo & DQO & \multicolumn{3}{|c|}{ \% de Remoción } \\
\hline 0 & 11500 & NA & NA & NA \\
\hline 8 & 3200 & 74,19 & 77,42 & 64,51 \\
\hline 15 & 2800 & 75,00 & 75,00 & 64,28 \\
\hline 22 & 2800 & 75,00 & 75,00 & 71,42 \\
\hline 29 & 2800 & 75,00 & 75,00 & 71,42 \\
\hline
\end{tabular}

$\mathrm{NA}=$ No Aplica

Fuente: los autores.

La estabilización de la materia orgánica está directamente relacionada con la producción de metano, que puede predecirse a partir de la Demanda Biológica de Oxígeno (DBO) o de la Demanda Química de Oxígeno (DQO) que han sido estabilizadas.

Según el decreto 1594 de 1984, los valores de remoción reflejados en el DQO deben ser mayores al $80 \%$ en carga. De acuerdo con lo anterior y comparado con los datos obtenidos en la tabla 2, es necesario realizar algún tipo de tratamiento posterior al efluente de los tres digestores antes de ser vertido, debido a que el porcentaje de remoción es muy cercano a lo exigido en la norma. El gráfico 1 muestra la relación de la DQO con respecto al tiempo para cada uno de los biodigestores, teniendo en cuenta que el valor final de DQO para el alimento se determinó promediando los resultados de las cuatro muestras.

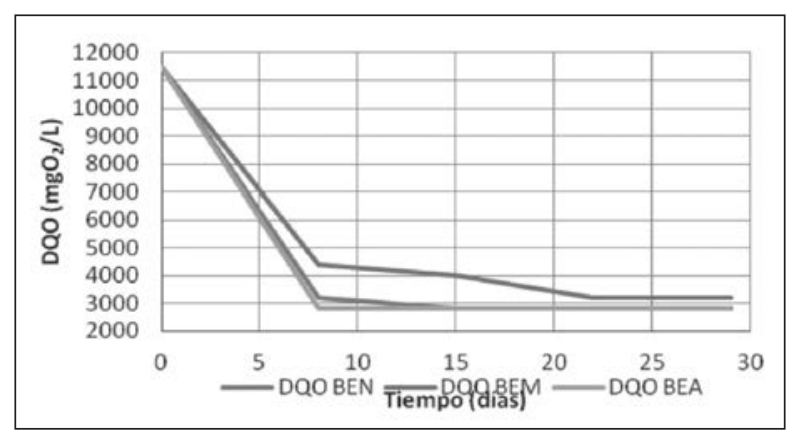

Figura 3. Comparación de la reducción y estabilización del DQO 
Del análisis del gráfico 1 se determina que el biodigestor que mostró mejor desempeño en cuanto a la estabilización y remoción de la DQO es el BEA comparado con el BEN; así mismo se infiere que el BEM no es una buena opción ya que su porcentaje de remoción de DQO es baja y además el tiempo de estabilización es mucho más largo que los demás.

\section{Sólidos Suspendidos (SS) y Sólidos Fijos (SF)}

Tabla 3. Resultados pruebas experimentales para sólidos

\begin{tabular}{|l|l|c|c|c|r|r|}
\hline Muestra & Tipo & Pf $(\mathbf{g})$ & Pi $(\mathbf{g})$ & PT (g) & SS (mg/L) & SF (mg/L) \\
\hline \multirow{4}{*}{} & Alimento & 0,6165 & 0,1234 & 0,4931 & 246550 & 355 \\
\cline { 2 - 7 } & BEN & 0,1405 & 0,1209 & 0,0196 & 9800 & 58 \\
\cline { 2 - 7 } & BEM & 0,2880 & 0,1240 & 0,1640 & 82000 & 204 \\
\cline { 2 - 7 } & BEA & 0,1521 & 0,1244 & 0,0277 & 13850 & 88 \\
\hline \multirow{4}{*}{2} & Alimento & 0,5907 & 0,1216 & 0,4691 & 234550 & 298 \\
\cline { 2 - 7 } & BEN & 0,1381 & 0,1199 & 0,0182 & 9100 & 92 \\
\cline { 2 - 7 } & BEM & 0,2512 & 0,1257 & 0,1255 & 62750 & 199 \\
\cline { 2 - 7 } & BEA & 0,1527 & 0,1223 & 0,0304 & 15200 & 61 \\
\hline \multirow{5}{*}{} & Alimento & 0,6065 & 0,1235 & 0,4830 & 241500 & 324 \\
\cline { 2 - 7 } & BEN & 0,1535 & 0,1196 & 0,0339 & 16950 & 40 \\
\cline { 2 - 7 } & BEM & 0,2214 & 0,1200 & 0,1014 & 50700 & 185 \\
\cline { 2 - 7 } & BEA & 0,1539 & 0,1187 & 0,0352 & 17600 & 76 \\
\hline
\end{tabular}

Fuente: los autores.

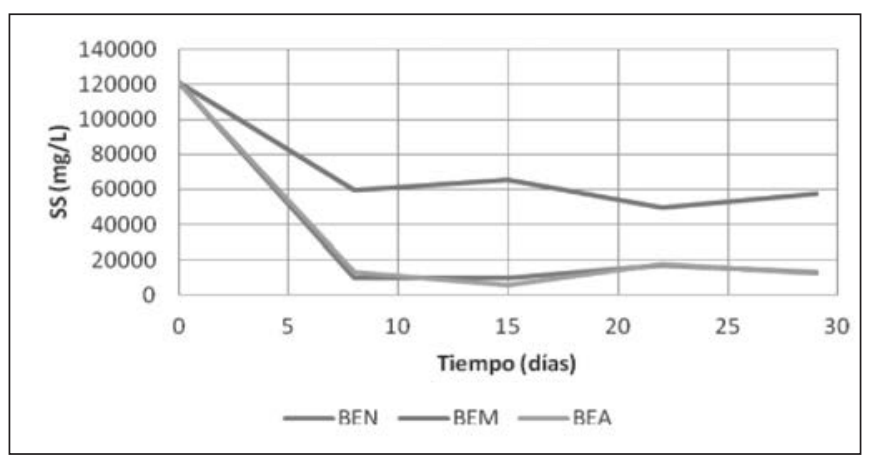

Figura 4. Variación de sólidos suspendidos 
Los sólidos suspendidos se refieren principalmente a la cantidad de materia orgánica que puede llegar a ser removida por medios físicos. En la figura 2 se muestra la variación de estos con respecto al tiempo en cada uno de los biodigestores; teniendo en cuenta que el decreto 1594 de 1984 especifica que la remoción de este tipo de sólidos debe superar el $80 \%$, cabe resaltar que esto se cumple a cabalidad en BEN y BEA. De otra parte, el BEM no cumple con la normatividad establecida, debido a que la carga microbiana contenida en el EM, aunque favorece características como el poder calorífico del gas producido y agiliza la transformación de materia orgánica, requiere de un tiempo más prolongado para obtener una adecuada remoción en carga, no sólo de sólidos suspendidos, sino de DQO.

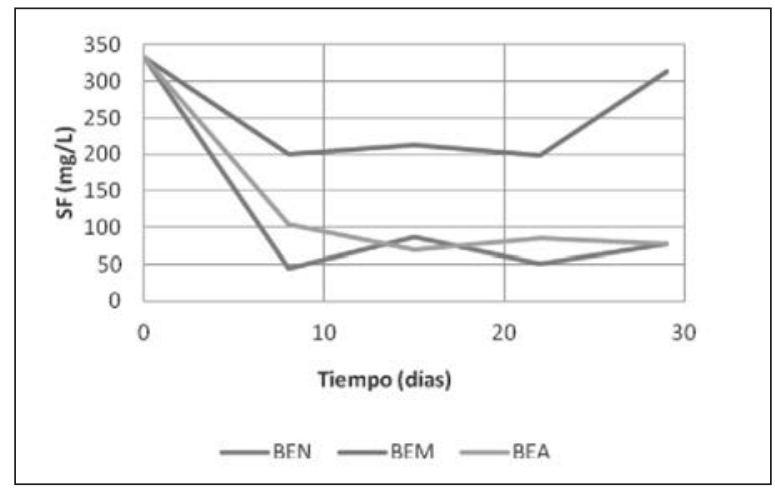

Figura 5. Variación de sólidos fijos

\section{Comportamiento del pH y Temperatura}

La figura 4 muestra un descenso importante de $\mathrm{pH}$, debido a que en los primeros ocho días es evidente una variación constante, seguida de una estabilización pausada del pH, hasta más o menos el día 26, donde definitivamente se detienen los cambios. Este descenso se debe a la producción de ácidos grasos volátiles (AGV) por la actividad acidogénica que tienen algunas bacterias contenidas en la materia orgánica, al inicio del proceso. Es de resaltar que el estiércol de cerdo contiene una fracción amoniacal, la cual corresponde en un $60 \%$ al nitrógeno total producido, mientras que el $40 \%$ restante equivale a materia orgánica, motivo por el cual los biodigestores iniciaron su proceso en un rango de $\mathrm{pH}$ no óptimo para la producción de gas. 
Tabla 4. Datos tabulados de $\mathrm{pH}$ y temperatura

\begin{tabular}{|l|c|c|c|c|c|c|}
\hline \multirow{2}{*}{ Tiempo (días) } & \multicolumn{3}{|c|}{$\mathbf{p H}$} & \multicolumn{3}{|c|}{ TEMPERATURA $\left({ }^{\circ} \mathbf{C}\right)$} \\
\cline { 2 - 7 } & BEN & BEM & BEA & BEN & BEM & BEA \\
\hline $\begin{array}{l}\text { Primer } \\
\text { Alimento }\end{array}$ & 8,1 & 8,1 & 8,1 & 18 & 18 & 18 \\
\hline 2 & 7,9 & 7,9 & 7,9 & 22 & 20 & 24 \\
\hline 4 & 7,4 & 7,5 & 7,5 & 23 & 21 & 26 \\
\hline 6 & 7,4 & 7,4 & 7,4 & 23 & 23 & 28 \\
\hline 8 & 7,1 & 7,1 & 7 & 25 & 24 & 27 \\
\hline 10 & 6,8 & 7,1 & 6,9 & 24 & 23 & 28 \\
\hline 12 & 6,8 & 6,9 & 6,9 & 23 & 22 & 28 \\
\hline 14 & 7 & 6,8 & 6,9 & 22 & 24 & 29 \\
\hline 16 & 7 & 6,8 & 6,8 & 24 & 25 & 30 \\
\hline 18 & 6,9 & 6,7 & 6,8 & 24 & 25 & 29 \\
\hline 20 & 6,8 & 6,7 & 7 & 23 & 24 & 29 \\
\hline 22 & 6,7 & 6,9 & 6,9 & 23 & 24 & 31 \\
\hline 24 & 6,7 & 6,9 & 6,8 & 25 & 23 & 28 \\
\hline 26 & 6,7 & 7 & 6,8 & 23 & 24 & 29 \\
\hline 28 & 6,7 & 7 & 6,8 & 23 & 24 & 29 \\
\hline 30 & 6,7 & 7 & 6,8 & 23 & 24 & 29 \\
\hline
\end{tabular}

Fuente: los autores.

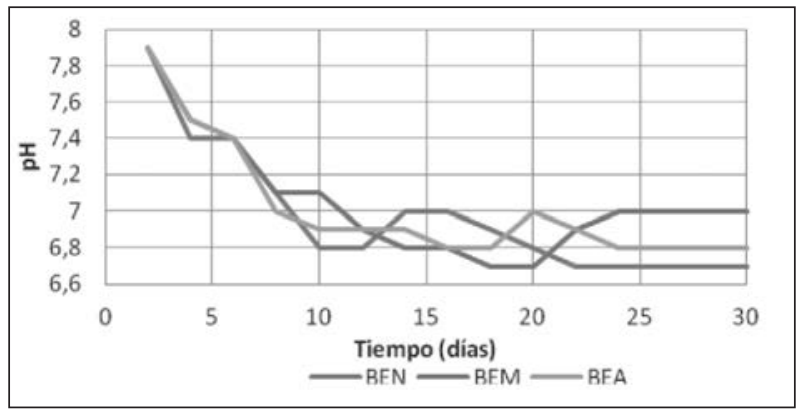

Figura 6. Comportamiento del $\mathrm{pH}$

El comportamiento del gráfico 5 para el BEA está dentro del rango de los mesófilos, ya que en este tipo de microorganismos, a mayor temperatura, más eficiente la actividad microbiana; sin embargo el crecimiento de bacterias metanogénicas para BEN y BEM es 
un poco deficiente. Esto quiere decir que la estabilización de la temperatura se encuentra alrededor del día 14 para el BEA, marcando una presión de 3,6 psi en el manómetro instalado, lo que es favorable para la producción de gas y para mantener el DQO dentro del rango observado en el gráfico 1 .

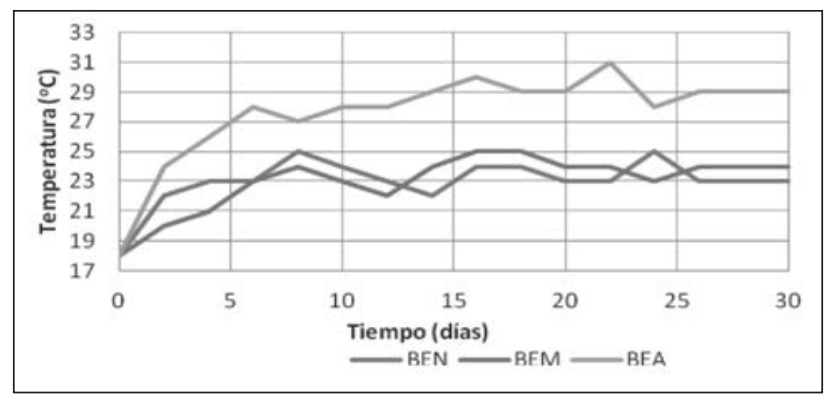

Figura 7. Comportamiento de la temperatura

\section{Selección del sistema de tratamiento}

Tabla 5. Selección del sistema con variables de respuesta

\begin{tabular}{|l|c|c|c|}
\hline Criterios de Selección & BEN & BEM & BEA \\
\hline$\%$ de Remoción de DQO & + & - & + \\
\hline$\%$ de Remoción de Sólidos & ++ & - & ++ \\
\hline $\mathrm{Ph}$ & ++ & + & + \\
\hline Temperatura & ++ & + & + \\
\hline
\end{tabular}

$(++)$ Muy viable $(+)$ Viable (-) No viable

Según la tabla 5, el digestor experimental que mejor se acopló a las condiciones de operación fue el BEA, puesto que no solo se estabiliza en un tiempo menor a los otros dos, sino que la producción de gas es bastante buena, razón por la cual, el digestor que mejor se acople de la tabla 6 , tendrá que tener un aislante para mejorar la producción de gas a las condiciones de operación a las cuales va a ser sometido. 
Tabla 6. Selección con consideraciones técnicas

\begin{tabular}{|l|c|c|c|c|c|}
\hline \multicolumn{1}{|c|}{ Criterios de Selección } & $\mathbf{1}$ & $\mathbf{2}$ & $\mathbf{3}$ & $\mathbf{4}$ & $\mathbf{5}$ \\
\hline Cantidad y calidad de biomasa disponible & + & + & ++ & ++ & ++ \\
\hline Condiciones de terreno & + & + & ++ & ++ & ++ \\
\hline Facilidad de operación y mantenimiento & - & - & ++ & ++ & ++ \\
\hline Temperatura & ++ & - & - & - & ++ \\
\hline Construcción & + & - & - & - & ++ \\
\hline Tiempo de retención & + & + & - & ++ & + \\
\hline Complejidad en la construcción y materiales & - & - & - & + & ++ \\
\hline Eficiencia en la conversión de gas & ++ & - & - & ++ & ++ \\
\hline Vida útil & + & + & - & - & - \\
\hline Deterioro de las piezas & + & + & ++ & ++ & + \\
\hline Reparaciones & - & - & + & + & ++ \\
\hline Lavado y vaciado & + & - & ++ & ++ & ++ \\
\hline Costos de construcción & - & - & - & - & ++ \\
\hline Costos de mantenimiento & + & + & - & - & ++ \\
\hline
\end{tabular}

(1) Biodigestores completamente mezclados. (++) Muy Viable.

(2) Biodigestor de dos etapas.

(+) Viable.

(3) Modelo chino.

(-) Poco viable.

(4) Modelo hindú.

(5) Modelo flexible o flujo pistón.

\section{INGENIERÍA BÁSICA}

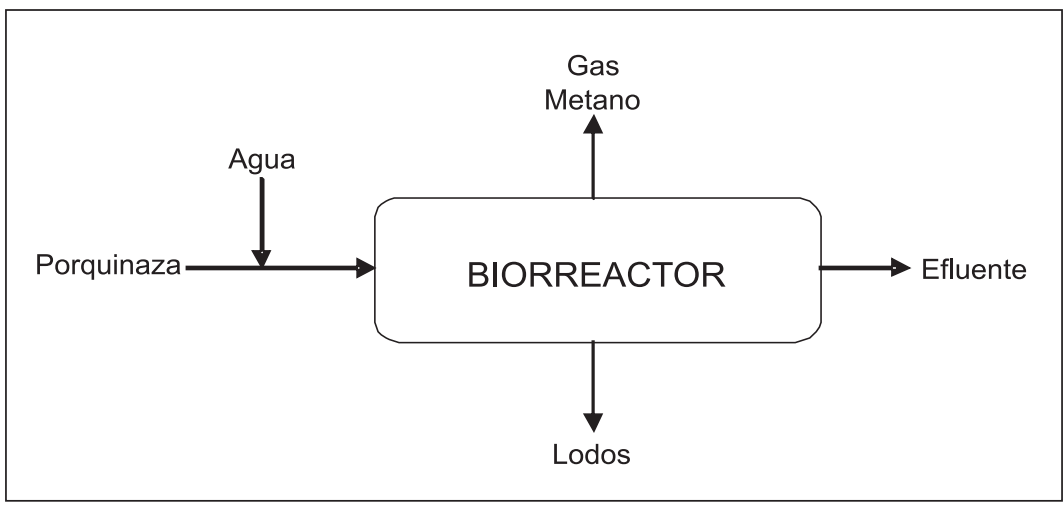

Figura 8. Diagrama del proceso 


\section{Producción estimada de biogás y dimensionamiento del biodigestor}

De acuerdo con la cantidad de materia orgánica que se obtiene en la finca por día, que actualmente es de $74,5 \mathrm{Kg}$, se realiza el cálculo de la cantidad de biogás que llegaría a producir el biodigestor.

$P E B=$ Masa de porquinaza $x \%$ MSO $x P P G$

Donde:

PEB = Producción Estimada de Biogás.

MSO = Materia Orgánica Soluble.

PPG = Promedio de Producción de Biogás.

$$
\begin{aligned}
& P E B=74,5 \mathrm{Kg} \times 0,12 \times 450 \frac{\mathrm{l}}{\mathrm{kg}}=4023 \frac{\mathrm{l}}{\mathrm{d} t \mathrm{a}}=4,023 \frac{\mathrm{m}^{\mathrm{s}}}{\mathrm{d} t \mathrm{a}} \\
& M_{m}=M P C+M_{H_{2}} \text { O } \\
& M_{\mathrm{m}}=74,5 \mathrm{~kg}+111.75 \mathrm{Kg} \\
& M_{m}=186,25 \mathrm{Kg}
\end{aligned}
$$

$$
\begin{aligned}
& V_{m}=\frac{M_{m}}{\rho_{m}} \\
& V_{m}=\frac{186,25 \mathrm{~kg}}{1205 \mathrm{~kg} / \mathrm{m}^{3}} \\
& V_{m}=0,1545 \mathrm{~m}^{3}=154,5 \mathrm{~L}
\end{aligned}
$$

$\mathrm{M}_{\mathrm{m}} \quad=$ Masa de mezcla.

$\rho \mathrm{m} \quad=$ Densidad de mezcla.

$\mathrm{V}_{\mathrm{m}} \quad=$ Volumen de mezcla.

Con base en la ecuación (6), se obtiene la masa de mezcla y con la ecuación (7), el volumen de mezcla del digestor a dimensiones reales Teniendo en cuenta que el volumen es de 5,44 L/min, lo anterior sin dejar de lado que la llave de la manguera permanece abierta hasta el tope, para cumplir con la relación agua - porquinasa, se debe verter agua durante 1,3 min, debido a que los requerimientos son de $116,7 \mathrm{~L}$ de agua para mezclar con la porquinaza, lo que equivale a $111,75 \mathrm{Kg}$ por su densidad de $0,999 \mathrm{Kg} / \mathrm{L}$. 
Teniendo la carga diaria disponible de $0,1545 \mathrm{~m}^{3}$, y un TRH de 30 días, se calcula el volumen para la fase líquida (alimento) correspondiente al $75 \%$ del volumen total del biodigestor, haciendo uso de la ecuación (8).

$$
V_{f l}=\operatorname{TRH} \times V_{m}
$$

Donde:

$\mathrm{V}_{\mathrm{fl}} \quad=$ Volumen de la fase líquida.

TRH $=$ Tiempo de retención hidráulico.

$\mathrm{V}_{\mathrm{m}} \quad=$ Volumen de mezcla.

$$
\begin{aligned}
& V_{f l}=30 \text { dias } \times 0,1545 \mathrm{~m}^{3} \\
& V_{f l}=4,635 \mathrm{~m}^{3}
\end{aligned}
$$

Puesto que la fase líquida del biodigestor corresponde a un $25 \%$, el volumen del depósito de biogás corresponde a:

$$
\begin{aligned}
& V_{d g}=1,545 \mathrm{~m}^{3} \\
& V_{B}=4,635 \mathrm{~m}^{3}+1,545 \mathrm{~m}^{3} \\
& V_{B}=6,18 \mathrm{~m}^{3}
\end{aligned}
$$

Donde:

$\mathrm{Vdg} \quad=$ Volumen del depósito de gas.

$\mathrm{VB}=$ Volumen total del biodigestor.

\section{Capacidad energética del sistema}

La finca Veraguas consume una pipeta de $60 \mathrm{lb}$ de gas propano mensualmente y, teóricamente, $1 \mathrm{~m}^{3}$ de biogás con una composición de $68 \%$ de $\mathrm{CH}_{4}$ tiene un poder calorífico de 5148,57 $\mathrm{Kcal} / \mathrm{m}^{3}$, en el caso del $\mathrm{C}_{3} \mathrm{H}_{8} 1 \mathrm{~m}^{3}$ equivale a $1,90 \mathrm{Kg}$ y produce una energía de 22000 $\mathrm{Kcal} / \mathrm{m}^{3}$.

Con la ecuación (9) se halla el poder calorífico del biogás $\left(\mathrm{P}_{\mathrm{cg}}\right)$ obtenido.

$$
\begin{aligned}
& P_{c g}=P_{c}\left(\mathrm{CH}_{4}\right) x X_{\mathrm{CH}_{4}} \\
& P_{c g}=3501,028 \frac{\mathrm{Kcal}}{\mathrm{m}^{3}}
\end{aligned}
$$


Para calcular el potencial de generación de energía $\left(\mathrm{P}_{\mathrm{GE}}\right)$ del biogás, se debe utilizar la ecuación (10) de la siguiente manera:

$$
\begin{aligned}
& P_{G E}=F_{\bar{B}} x P_{c g} \\
& P_{G E}=14084,64 \frac{\mathrm{Kcal}}{\mathrm{d} r a}
\end{aligned}
$$

Para obtener el consumo diario de $\mathrm{C}_{3} \mathrm{H}_{8}$ en la finca, se utiliza la ecuación (11), teniendo en cuenta que se tienen $27,22 \mathrm{Kg}$ después de realizar la conversión de las $60 \mathrm{lb}$ y utilizando la relación anteriormente nombrada se obtiene que esta masa equivale a $14,326 \mathrm{~m}^{3}$.

$$
\begin{aligned}
& C_{P D}=\frac{v_{C_{3} H_{8}}}{t_{6}} \\
& C_{P D}=0,4775 \frac{\mathrm{m}^{3}}{d t a}
\end{aligned}
$$

Donde:

$\mathrm{C}_{\mathrm{PD}} \quad=$ Consumo de propano diario.

$\mathrm{V}_{\mathrm{C} 3 \mathrm{H} 8} \quad=$ Volumen de propano.

$\mathrm{t}_{\mathrm{c}} \quad=$ Tiempo de consumo de propano.

La ecuación (12) permite obtener el consumo de energía de propano diario, así:

$$
\begin{aligned}
& C_{E P}=P_{C}\left(C_{3} H_{8}\right) \times C_{P D} \\
& C_{E P}=10505,96 \frac{\mathrm{Kcal}}{\mathrm{d} t a}
\end{aligned}
$$

Donde,

$\mathrm{C}_{\mathrm{EP}} \quad=$ Capacidad energética del propano.

$\mathrm{P}_{\mathrm{C}} \quad=$ Poder calorífico.

Los metros cúbicos de biogás requerido $\left(\mathrm{B}_{\mathrm{r}}\right)$ por día, para producir esta cantidad energética, está dada por la ecuación (13).

$$
\begin{aligned}
& B_{r}=\frac{C_{E F}}{P_{c g}} \\
& B_{r}=3,00 \frac{\mathrm{m}^{3}}{d r a}
\end{aligned}
$$

Según los anteriores cálculos, se evidencia que la producción de gas a la hora de implementar el sistema en la finca, estaría cumpliendo con sus requerimientos energéticos y evidenciando una sobreproducción, lo que haría pensar que en un futuro, se podría llegar a utilizar este gas en exceso con otros fines. 


\section{Relación beneficio costo}

Por medio de los flujos de caja, tanto de la situación actual como del proyecto propuesto, expuestos en la tabla 8, se halló la relación beneficio-costo de cada uno, obteniendo los siguientes resultados:

$$
\begin{array}{ll}
\mathrm{B} / \mathrm{C}(\text { Actual }) & =1,04447 \\
\mathrm{~B} / \mathrm{C}(\text { Proyecto }) & =1,10938
\end{array}
$$

Para realizar los flujos de caja, se tomó un estimado de duración del proyecto de 10 años, tiempo aproximado de vida útil de la geomembrana. Con lo anterior y conociendo el promedio de la inflación de los últimos 5 años que es del 5,7\%, se aumentó a partir del año 1 esta cifra, en cada uno de los valores que componen los flujos de caja, tanto egresos como ingresos, para tener un resultado mucho más real.

Teniendo en cuenta que la relación beneficio-costo de un proyecto de inversión toma los ingresos y los egresos netos para determinar cuáles son los beneficios por cada peso que se sacrifica, es claro que efectivamente al realizar la inversión, dicha relación es mayor que la que se genera al continuar utilizando gas propano como recurso energético. Esta situación se hace más evidente al comparar los valores de utilidad neta a lo largo de los 10 años donde $\$ 32$ '446.498 corresponden a la utilidad que generaría la finca en caso de continuar con el sistema actual y \$47’032.078 lo que se generaría si se implementara el sistema propuesto en el presente proyecto; esto da una diferencia de $\$ 14.585 .580$, lo que representa una ganancia significativa para una finca autosostenible como esta. En este orden de ideas, la inversión se recuperaría en 14 meses, desde el momento en que se implementa el digestor.

Por lo anterior, la propuesta realizada a las personas propietarias de la finca Veraguas, es completamente viable, y sólo dependería principalmente de la disponibilidad económica actual para realizar la respectiva inversión, teniendo en cuenta que los alcances del proyecto, no se encuentran reflejados únicamente a la hora de hablar de ahorro sino, pensando en la posibilidad de tener ingresos a partir de productos como el biogás adicional generado y el efluente, que complementado con un sistema de filtración y análisis pertinentes, estaría apto para usar como fertilizante. 
Tabla 7. Flujo de caja para la situación actual

\begin{tabular}{|l|r|r|r|r|r|r|}
\hline & Año 0 & Año 1 & Año 2 & Año 3 & Año 4 & Año 5 \\
\hline Ingresos & & & & & \\
\hline Cocheras & 0,0 & $9.518 .580,0$ & $10.162 .226,4$ & $10.849 .396,1$ & 11.583 .0323 & $12.366 .276,9$ \\
\hline Cultivos & 0,0 & $1.929 .098,9$ & $2.040 .253,6$ & $2.157 .813,0$ & $2.282 .146,2$ & $2.413 .643,4$ \\
\hline Otros & 0,0 & $571.114,8$ & $604.022,4$ & $638.826,2$ & $675.635,4$ & $714.565,5$ \\
\hline Total Ingresos & 0,0 & $12.018 .793,7$ & $12.806 .502,4$ & $13.646 .035,3$ & $14.540 .813,8$ & $15.494 .485,8$ \\
\hline Egresos & & & & & & \\
\hline Luz & $480.000,0$ & $507.657,6$ & $536.908,8$ & $567.845,5$ & $600.564,8$ & $635.169,3$ \\
\hline Agua & $248,000,0$ & $262.289,8$ & $277.402,9$ & $293.386,9$ & $310.291,8$ & $328.170,8$ \\
\hline Comida Animales & $5.050 .000,0$ & $5.340 .981,0$ & $5.648 .728,3$ & $5.974 .208,1$ & $6.318 .441,9$ & $6.682 .510,5$ \\
\hline Semillas & $356.000,0$ & $376.512,7$ & 398207,4 & $421.152,1$ & $445.418,9$ & $471.083,9$ \\
\hline Abono & $1.745 .000,0$ & $1.845 .546,9$ & $1.951 .887,3$ & $2.064 .355,1$ & $2.183 .303,2$ & $2.309 .105,1$ \\
\hline Gas Propano & $1.564 .740,0$ & $1.654 .900,3$ & $1.750 .255,7$ & $1.851 .105,4$ & $1.957 .766,1$ & $2.070 .572,6$ \\
\hline Total Egresos & $9.443 .740,0$ & $9.987 .888,3$ & $10.563 .390,4$ & $11.172 .053,0$ & $11.815 .786,7$ & $12.496 .612,3$ \\
\hline Utilidad Neta & $-9.443 .740,0$ & $2.030 .905,4$ & $2.243 .111,9$ & $2.473 .982,3$ & $2.725 .027,1$ & $2.997 .873,5$ \\
\hline
\end{tabular}

\begin{tabular}{|l|r|r|r|r|r|}
\hline & \multicolumn{1}{|c|}{ Año 6 } & Año 7 & Año 8 & Año 9 & Ano 10 \\
\hline Ingresos & & & & & \\
\hline Cocheras & $13.202 .484,6$ & $14.095 .236,6$ & $15.048 .356,5$ & $16.065 .926,4$ & $17.152 .304,3$ \\
\hline Cultivos & $2.552 .717,5$ & $2.699 .805,1$ & 2.855 .367 .9 & $3.019 .894,2$ & 3.193 .900 .5 \\
\hline Otros & $755.738,7$ & $799.284,4$ & $845.339,2$ & $894.047,6$ & $945.562,6$ \\
\hline Total Ingresos & $16.510 .940,9$ & $17.594 .326,1$ & $18.749 .063,6$ & 19.979 .8682 & $21.291 .767,4$ \\
\hline Egresos & & & & & \\
\hline Luz & $671.767,8$ & $710.475,0$ & $751.412,6$ & $794.709,0$ & $840.500,1$ \\
\hline Agua & $347.080,0$ & $367.078,8$ & $388.229,8$ & $410.599,7$ & $434.258,4$ \\
\hline Comida Animales & $7.067 .556,8$ & $7.474 .789,4$ & $7.905 .486,8$ & $8.361 .000,9$ & $8.842 .761,8$ \\
\hline Semillas & $498.227,8$ & $526.935,7$ & $557.297,7$ & $589.409,2$ & $623.370,9$ \\
\hline Abono & $2.442 .155,8$ & $2.582 .872,8$ & $2.731 .697,9$ & $2.889 .098,3$ & $3.055 .568,2$ \\
\hline Gas Propano & $2.189 .879,0$ & $2.316 .059,8$ & $2.449 .511,2$ & $2.590 .652,0$ & $2.739 .925,4$ \\
\hline Total Egresos & $13.216 .667,1$ & $13.978 .211,5$ & $14.783 .636,0$ & $15.635 .469,1$ & $16.536 .384,8$ \\
\hline Utilidad Neta & $3.294 .273,8$ & $3.616 .114,7$ & $3.965 .427,6$ & $4.344 .399,1$ & $4.755 .382,6$ \\
\hline
\end{tabular}

Fuente: los autores. 
Tabla 8. Flujo de caja para el proyecto

\begin{tabular}{|c|c|c|c|c|c|c|}
\hline & Año 0 & Año 1 & Año 2 & Año 3 & Año 4 & Año 5 \\
\hline \multicolumn{7}{|l|}{ Ingresos } \\
\hline Cocheras & 0,0 & $9.518 .580,0$ & $10.067040,6$ & 10.647 .1035 & 11.260 .5896 & 11.909 .4247 \\
\hline Cultivos & 0,0 & $1.929,098,9$ & 2.040 .253 .6 & $2.157 .813,0$ & 2.282 .146 .2 & $2.413 .643,4$ \\
\hline Otros & 0,0 & $571.114,8$ & $604.022,4$ & $638.826,2$ & $675.635,4$ & $714.565,5$ \\
\hline Total Ingresos & 0,0 & 12.018 .7937 & 12.711 .316 .6 & 13.443 .742 .6 & 14.218 .371 .1 & 15.037 .633 .6 \\
\hline \multicolumn{7}{|l|}{ Egresos } \\
\hline Luz & $480.000,0$ & $507.657,6$ & 536.908 .8 & 567.845 .5 & 600.564 .8 & $635.169,3$ \\
\hline Agua & 248.000 .0 & 262.289 .8 & $277.402,9$ & $293.386,9$ & $310.291,8$ & $328.170,8$ \\
\hline Comida Animales & 5.050 .000 .0 & $5.340 .981,0$ & $5.648 .728,3$ & 5.974 .2081 & $6.318 .441,9$ & $6.682 .510,5$ \\
\hline Semillas & $356.000,0$ & $376.512,7$ & 398.2074 & $421.152,1$ & $445.418,9$ & $471.083,9$ \\
\hline Abono & $1.745,000,0$ & 1.845 .546 .9 & 19518873 & 2.064 .355 .1 & 2.183 .303 .2 & $2.309 .105,1$ \\
\hline Inver, Biodigestor & 1.716 .300 .0 & $114.223,0$ & $139.605,8$ & 139.605 .8 & $139.605,8$ & $139.605,8$ \\
\hline Total Egresos & 9.595 .300 .0 & $8.447 .210,9$ & $8.952 .740,6$ & $9.460 .553,4$ & $9.997 .626,4$ & 10.565 .645 .6 \\
\hline Utilidad Neta & $-9.595 .300,0$ & $3.571 .582,7$ & $3.758 .576,0$ & 3.983 .189 .2 & $4.220 .744,7$ & 4.471 .988 .1 \\
\hline
\end{tabular}

\begin{tabular}{|l|r|r|r|r|r|}
\hline & \multicolumn{1}{|c|}{ Año 6 } & \multicolumn{1}{|c|}{ Año 7 } & \multicolumn{1}{c|}{ Año 8 } & \multicolumn{1}{|c|}{ Año 9 } & \multicolumn{1}{c|}{ Año 10 } \\
\hline Ingresos & & & & & \\
\hline Cocheras & $12.595 .645,8$ & $13.321,406,9$ & $14.088 .986,4$ & $14,900.793,8$ & $15.759 .377,5$ \\
\hline Cultivos & $2.552 .717,5$ & $2.699 .805,1$ & $2.855 .367,9$ & $3.019 .894,2$ & $3.193 .900,5$ \\
\hline Otros & $755.738,7$ & $799.284,4$ & $845.339,2$ & $894.047,6$ & $945.562,6$ \\
\hline Total Ingresos & $15.904 .102,1$ & $16.820 .496,4$ & $17.789 .693,4$ & $18.814 .735,6$ & $19.898 .840,6$ \\
\hline Egresos & & & & & \\
\hline Luz & $671.767,8$ & $710.475,0$ & $751.412,6$ & $794.709,0$ & $840.500,1$ \\
\hline Agua & $347.080,0$ & $367.078,8$ & $388.229,8$ & $410.599,7$ & $434.258,4$ \\
\hline Comida Animales & $7.067 .556,8$ & $7.474 .789,4$ & $7.905 .486,8$ & $8.361 .000,9$ & $8.842 .761,8$ \\
\hline Semillas & $498.227,8$ & $526.935,7$ & $557.297,7$ & $589.409,2$ & $623.370,9$ \\
\hline Abono & $2.442 .155,8$ & $2.582 .872,8$ & $2.731 .697,9$ & $2.889 .098,3$ & $3.055 .568,2$ \\
\hline Inversión Biodigestor & $139.605,8$ & $139.605,8$ & $139.605,8$ & $139.605,8$ & $139.605,8$ \\
\hline Total Egresos & $11.166 .394,0$ & $11.801 .757,5$ & $12.473 .730,7$ & $13.184 .422,9$ & $13.936 .065,3$ \\
\hline Utilidad Neta & $4.737 .708,1$ & $5.018 .738,9$ & $5.315 .962,8$ & $5.630 .312,6$ & $5.962 .775,3$ \\
\hline
\end{tabular}

Fuente: los autores.

\section{CONCLUSIONES}

De acuerdo con la caracterización realizada a la materia orgánica se obtuvo una relación Carbono-Nitrógeno $(\mathrm{C} / \mathrm{N})$ de 15 , valor que se encuentra entre el rango óptimo, lo que indica que la excreta recolectada en las cocheras de la finca es adecuada para ser utilizada en este tipo de procesos, y se estableció que elementos como el $\mathrm{Cu}, \mathrm{K}$, $\mathrm{Ca}$ y $\mathrm{Na}$, no presentan características de inhibición para las bacterias metanogénicas.

Se tomaron las variables de respuesta como lo son $\mathrm{pH}$, temperatura, DQO, sólidos suspendidos y sólidos fijos, para evaluar la eficiencia de los tres biodigestores experimentales a condiciones ambientales normales, lo que dio como resultado que el sistema que mejor se acoplaba a estas condiciones era el BEA, ya que en las pruebas que se le hicieron fue el que mejor desempeño tuvo. Tanto la temperatura como el $\mathrm{pH}$, para cada uno de los biodigestores experimentales, se encuentran en un rango aceptable, ya que el tiempo de 
estabilización es relativamente corto; sin embargo, a la hora de definir cuál de ellos presenta un mejor desempeño respecto a a estas dos variables, cabe resaltar que en cuanto a $\mathrm{pH}$, haciendo una comparación entre el BEN y el BEA, se tiene que el segundo presenta una estabilización en el día 24, lo que significa que la producción de gas por efecto de la metanogénesis será más rápida. Y en cuanto a la temperatura, el BEA se encuentra entre $24-29^{\circ} \mathrm{C}$, rango adecuado para los microorganismos mesófilos, lo que indica un tiempo menor de producción y de estabilización.

$\mathrm{Al}$ analizar la producción de materia orgánica partiendo de la cantidad de animales con que cuenta actualmente la finca, se determinó que la masa total para mezclar con agua según la relación 1:1,5, es de $74,5 \mathrm{Kg}$, con lo cual se tendría una producción de biogás de 4,023 m día o el equivalente a $14084,64 \mathrm{Kcal} /$ día, valor que sobrepasa los requerimientos energéticos para la cocción de alimentos en un $34,06 \%$, sabiendo que con respecto al gas propano, se consumen actualmente 10505,96 Kcal/día.

Con respecto al diseño del biodigestor, se determinó por medio de los cálculos, que éste debe tener un volumen de $6,18 \mathrm{~m}^{3}, 5,62 \mathrm{~m}$ de longitud y un diámetro de $1,2 \mathrm{~m}$, teniendo en cuenta que el tiempo de retención hidráulico será de 30 días. Para asegurar la protección del sistema (geomembrana y cajas de recepción) de la lluvia y ayudar a mantener una temperatura constante, se estableció la necesidad de cubrirlo con un plástico transparente en forma de invernadero.

La construcción de un sistema de biodigestión en la finca Veraguas, según las especificaciones de este proyecto, se muestra viable, gracias a que primero, se convierte en una alternativa de producción de energía más limpia, eliminando principalmente los malos olores y las vertientes contaminantes; segundo, la utilidad neta al finalizar los diez años estimados de vida útil, es de $\$ 14$ '585.580 más que si se continuara con la actividad actual $\mathrm{y}$, finalmente, se tendría la posibilidad, previo a un tratamiento como lo indican las recomendaciones, de usar el efluente como fertilizante, no sólo para satisfacer las necesidades de la finca, sino para venta externa y así obtener un ingreso adicional. También se debe tener en cuenta que el tiempo de recuperación de la inversión es corto comparado con el de los años de servicio. Cabe acotar que el tiempo de durabilidad puede llegar a alcanzar los 15 años, lo que aumentaría el beneficio de este proyecto.

\section{REFERENCIAS BIBLIOGRÁFICAS}

AGROSOIL LAB. 2004. Registro ICA para el control de calidad de fertilizantes: Resolución 01320 de Junio.

AMAYA CABRERA, Camilo Andrés y BOLÍVAR GARZÓN, Iván Mauricio. 2008. Diseño de un Sistema de Aprovechamiento de Excreta Porcina Para la Generación de Biogás en la Granja Integral María Alejandra. Trabajo de grado Ingeniería Química. Bogotá D.C.: Universidad de América. Facultad de Ingeniería. Departamento de Ingeniería Química. 
BOTERO BOTERO, Raúl Y R. PRESTON Thomas. 1987. Biodigestor de Bajo Costo para la Producción de Combustible y Fertilizante a partir de Excretas. Cali, Colombia.

COLMENARES MAYANGA, Wagner y SANTOS BONILLA, Karin. Generación y manejo de gases en sitios de disposición final. Disponible en Internet $<$ http://www.ingenieriaquimica. org/articulos/relleno_sanitario>. Consultado el día 23 de junio de 2009.

COLOMBIA. MINISTERIO DE LA PROTECCIÓN SOCIAL. Decreto 1594 (26, Junio, 1984). Por el cual se reglamenta parcialmente el Título 1 de la Ley 09 de 1979, así como el Capítulo II del Título VI - Parte III - Libro II y el Título III de la parte III - Libro I del Decreto 2811 de 1974 en cuanto a Usos del Agua y Residuos Líquidos. Bogotá: El Ministerio, 1984. 52 p.

CORANTIOQUIA. 2003. Corporación Regional del Centro de Antioquia. Cartilla de Manejo y Evaluación de la Porquinaza Mediante Procesos de Compostación. Universidad de Antioquia, Medellín.

MELO HERNÁNDEZ, Julián Emilio. 2006. Propuesta para el Aprovechamiento de los Residuos Orgánicos Producidos en la Granja Integral de la Fundación Formemos. Trabajo de grado Ingeniería Química. Bogotá D.C.: Universidad de América. Facultad de Ingeniería. Departamento de Ingeniería Química.

MOLINA TIRADO, Kevin Giovanni. 1999. Tratamiento de la excretas de cerdo mediante un reactor anaerobio SCFBR a nivel de banco. Trabajo de grado Ingeniería Química. Bogotá D.C.: Universidad Nacional de Colombia. Facultad de Ingeniería. Departamento de Ingeniería Química.

OSPINA MORENO, Sonia Katherine. 2007. Diseño de un Biodigestor para la Obtención de Gas Metano y Biofertilizantes en una Granja Autosostenible. Trabajo de grado Ingeniería Química. Bogotá D.C.: Fundación Universidad de América. Facultad de Ingeniería. Departamento de Ingeniería Química.

PIEDRAHITA, V. Daniel. 2000. Elementos Para una Tecnología Sobre la Producción de Biogás. Universidad Nacional de Colombia, Medellín, Facultad de ciencias Agropecuarias.

PINTO E. y MORENO E. 2002. Guía Ambiental para el Subsector Porcícola. Dirección General Ambiental Sectorial. 